\title{
THERMAL DESORPTION OF POTASSIUM FROM CLEAN AND SULFUR COVERED NICKEL
}

\author{
R. Blaszczyszyn, M. Blaszczyszynowa and W. Gubernator \\ Institute of Experimental Physics, University of Wrocław \\ Pl. Maxa Borna 9, 50-204 Wrocław, Poland \\ (Received May 31, 1995; revised version July 18, 1995)
}

\begin{abstract}
Activation energy for thermal desorption of potassium from clean and sulfur covered surfaces of nickel was determined by means of the field emission method. For the low potassium coverage limit $\left(\Theta_{K} \approx 0.02\right)$ the desorption was detected from the whole emitter surface in the temperature range of $825-1000 \mathrm{~K}$ for the atoms and of $725-825 \mathrm{~K}$ for the species of atoms and ions of the potassium. The activation energies of neutral desorption were found to be $E_{\mathrm{Ni}}^{\mathrm{a}}=3.8 \mathrm{eV}$ for the clean nickel and $E_{\mathrm{S} / \mathrm{Ni}}^{\mathrm{a}}=3.0 \mathrm{eV}$ for the sulfur covered nickel, $\Theta_{\mathrm{S}} \approx 0.5$. The activation energies for the desorption of the species of atoms and ions increased from $E_{\mathrm{Ni}}^{\mathrm{a}+\mathrm{i}}=2.5 \mathrm{eV}$ for the clean nickel to $E_{\mathrm{S} / \mathrm{Ni}}^{\mathrm{a}+\mathrm{i}}=2.9 \mathrm{eV}$ for the sulfur covered nickel $\Theta_{\mathrm{S}} \approx 0.5$. Also, a value of $E_{\mathrm{S}^{\prime} / \mathrm{Ni}}^{\mathrm{a}}=4.1 \mathrm{eV}$ was found for a higher coverage of sulfur, $\Theta_{\mathrm{S}} \approx 1$. The results are discussed in terms of Gurney model.
\end{abstract}

PACS numbers: 73.30.+y, 79.60.Dp, 79.90.+b

\section{Introduction}

This work is a completion of our experimental studies of the K-S/Ni system by using field electron emission microscopy methods (FEM). In particular, we have investigated the influence of adsorbed sulfur on the self-diffusion of nickel [1] and on the diffusion of potassium on nickel [2]. Those experiments showed that the presence of sulfur on the nickel surface produces increase in the activation energy of the self-diffusion of nickel as well as in the activation energy of the surface diffusion of potassium on nickel. Since the understanding of the influence of the adsorbed sulfur on the mechanism of the catalytic processes is still incomplete it would be desirable to have more information on the binding energy of potassium with sulfur covered nickel.

The present paper reports experimental results concerning studies of the thermal desorption (TD) of potassium from a clean and sulfur precovered nickel surface. The investigations were performed with application of the FEM method. 


\section{Experimental}

The experiments were carried out using a sealed-oft glass field-emission tube equipped with ampule-type sources of sulfur and potassium. The tube was immersed in liquid nitrogen providing a pressure below $10^{-9} \mathrm{~Pa}$. Nickel emitters were prepared by etching and spot welding a piece of the $99.995 \%$ purity wire to a nickel support loop. The emitter temperature was determined measuring the changes of resistance of a loop segment. The sulfur and potassium sources used in these experiments were similar to those described elsewhere $[3,4]$.

After the thermal cleaning of $\mathrm{Ni}$ emitter two types of the experiments were performed, namely the TD of potassium from: (I) clean nickel surface within the temperature range 775-910 K, and (II) sulfur precovered nickel surface (at average coverage $\Theta_{S}=0.5$ and $\Theta_{S}=1$ ) within the temperature range $725-1000 \mathrm{~K}$.

Assuming the first-order kinetics for desorption at a constant temperature $T$, if $\Theta_{\mathrm{K} 1}$ is the coverage at time $t_{1}$ and $\Theta_{\mathrm{K} 2}$ at time $t_{2}$ we have

$$
\ln \left(\Theta_{\mathrm{K} 1} / \Theta_{\mathrm{K} 2}\right)=t_{\mathrm{c}} \nu \exp (-E / R T),
$$

where $\nu$ contains an "attempt to-escape" frequency together with a small entropy term, $t_{c}=t_{2}-t_{1}$, and $E$ is the activation energy for TD. The activation energy for desorption was determined for the potassium coverage within the range $0<$ $\Theta_{\mathrm{K}}<0.02$ from the Arrhenius-type plots of $\ln t_{\mathrm{c}}$ vs. $1 / T$ as follows:

(i) Deposition of a potassium dose onto the clean (or sulfur precovered) $\mathrm{Ni}$ emitter at $78 \mathrm{~K}$.

(ii) Heating of the emitter at about $300 \mathrm{~K}$ in the absence of the electric field to enable equilibration by the surface diffusion of potassium.

(iii) Heating of the emitter for some time at a convenient temperature in the absence of high electric field but with a bias potential on the emitter with respect to the rest of the tube. In order to permit the ionic evaporation the emitter bias voltage was positive. Any value of the potential from 14 to $23 \mathrm{~V}$ could be applied. Desorption of neutrals was observed when the tip voltage was -14 to $-23 \mathrm{~V}$.

(iv) Measurements of the emission high voltage $U$ (which corresponds to the potassium coverage $\Theta_{K}$ ) for a fixed emission current as a function of the annealing time $t$ of the emitter at a constant temperature $T$, and determination of the $U$ vs. $\ln t$ dependence.

(v) Determination of the desorption times $t_{c}$ as a function of the substrate temperature $T$.

(vi) Calculation of the activation energies for thermal desorption of potassium, $E$, from the plots of $\ln t_{\mathrm{c}}$ vs. $1 / T$.

\section{Results and discussion}

Thermal desorption of $\mathrm{K}$ atoms from the $\mathrm{Ni}$ emitter (with the negative bias voltage on) was measured over the temperature range from 825 to $1000 \mathrm{~K}$. Representative voltage-time curves of $U$ vs. $\ln t$ at 825 and $860 \mathrm{~K}$ are shown in Fig. 1, when the tip voltage was $-14 \mathrm{~V}$. Example of field emission patterns for the desorption of potassium from the clean emitter is shown in Fig. 4b, c. 


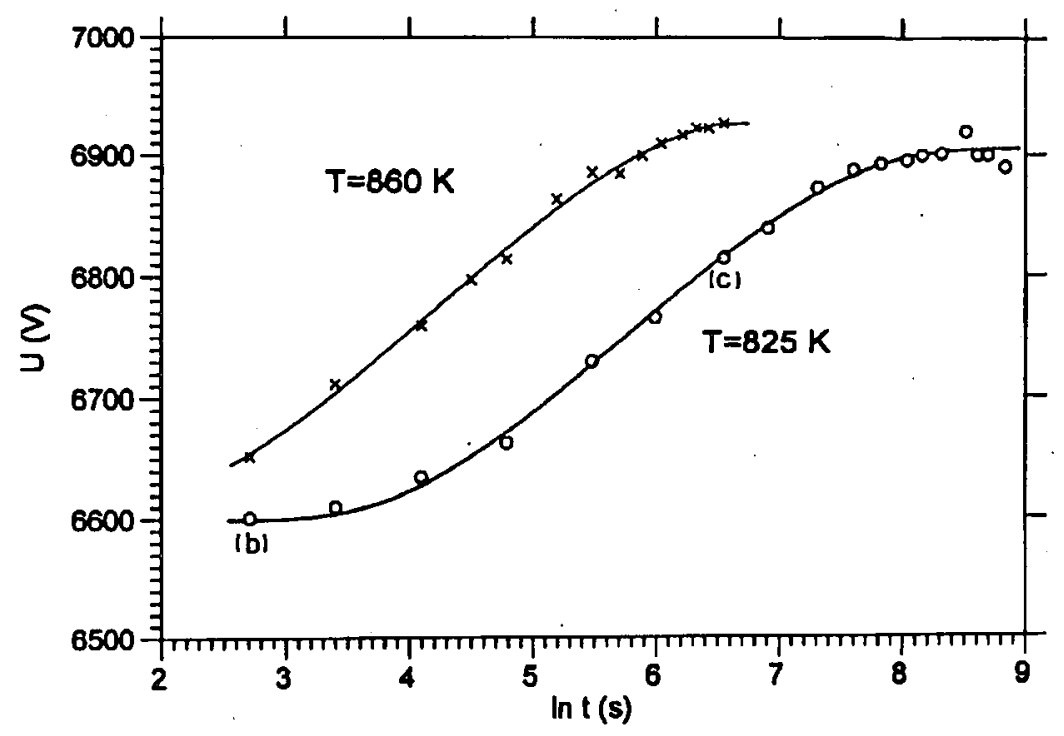

Fig. 1. Voltage $U$ required to maintain a constant emission current as a function of the desorption time of potassium atoms from nickel surface. The desorption was carried out at 825 and at $860 \mathrm{~K}$. Letters indicate the corresponding photographs in Fig. $4 \mathrm{~b}$ and c.

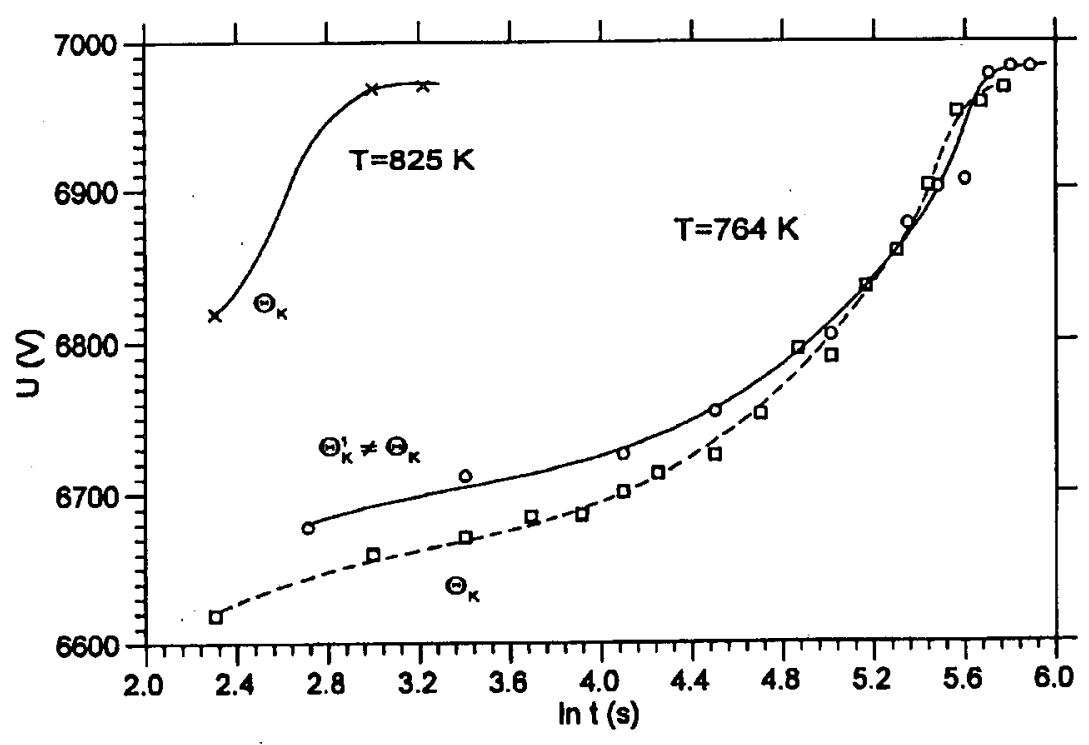

Fig. 2. Voltage $U$ required to maintain a constant emission current as a function of the desorption time of potassium atoms and ions from nickel surface. The desorption was carried out at $764 \mathrm{~K}$ for two different potassium coverages (see text) and at $825 \mathrm{~K}$. 
Measurements of the TD, with a positive bias voltage on in order to permit the ionic evaporation, were performed in the temperature range from 725 to $825 \mathrm{~K}$. Figure 2 shows the example of the $U$ vs. $\ln t$ curves for 825 and $764 \mathrm{~K}$, when the emitter tip potential applied was $+14 \mathrm{~V}$. Unfortunately, it was not possible to subtract the neutral from total (ions plus neutrals) desorption curve because of the different temperature intervals of these measurements.

The curves of Fig. 1 and 2 exhibit an increase in the $U$ values towards the value corresponding to the clean Ni surface which is achieved after time $t_{\mathrm{c}}$ at the temperature $T$. It was found that the time $t_{\mathrm{c}}$ did not strongly depend on the potassium coverage $\theta_{\mathrm{K}}$. The results of such measurements are shown in Fig. 2 for $\Theta_{\mathrm{K}}$ and $\Theta_{\mathrm{K}}^{\prime}\left(\Theta_{\mathrm{K}}>\Theta_{\mathrm{K}}^{\prime}\right)$ at $764 \mathrm{~K}$. It must therefore be concluded that the activation energy does not depend strongly on the potassium coverage for the small coverage.

Figure 3 shows typical $U$ vs. $\ln t_{\mathrm{c}}$ curves for the sulfur precovered $\mathrm{Ni}$ emitter $\left(\Theta_{\mathrm{S}} \approx 0.5\right)$, which were obtained at $725 \mathrm{~K}$ for the total desorption and at $880 \mathrm{~K}$ for the neutral desorption. Typical stages of this process are shown in Figs. 4e, $\mathrm{f}$. Similarly as in the case of the clean $\mathrm{Ni}$ emitter, it was not possible to obtain the individual rates of the ionic and neutral desorption because the temperatures required for the total desorption $(725-764 \mathrm{~K})$ were lower than those required for the atomic desorption $(880-1000 \mathrm{~K})$.

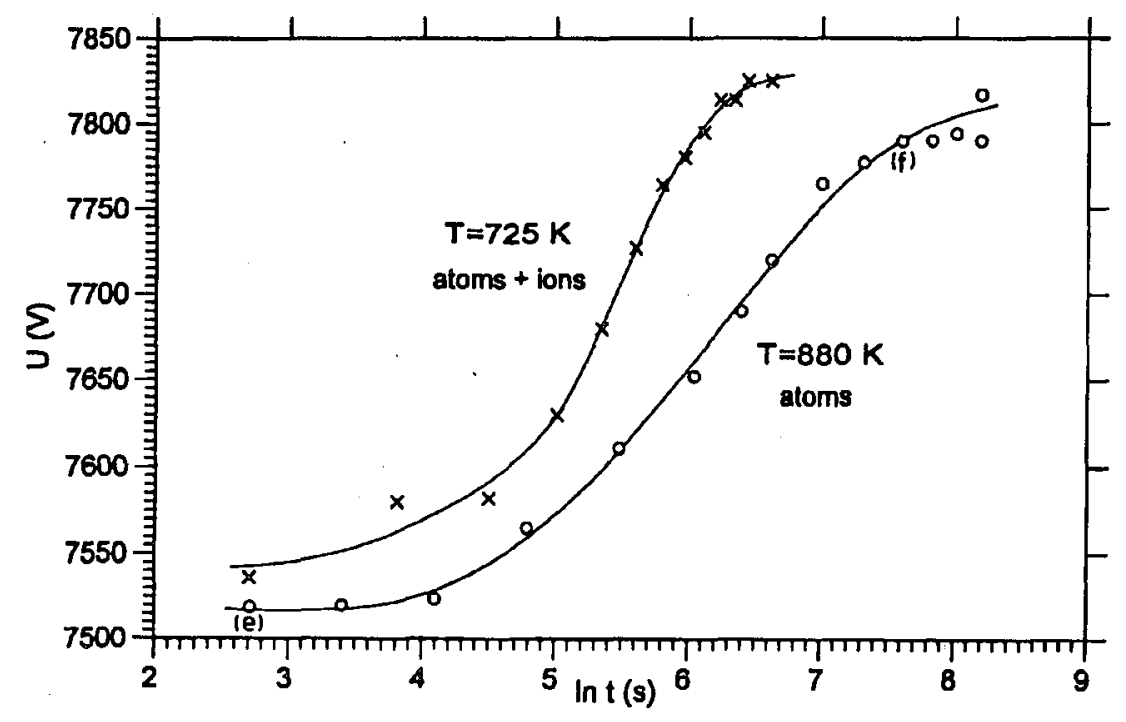

Fig. 3. Voltage $U$ required to maintain a constant emission current as a function of the desorption time of potassium from sulfur covered nickel $\left(\Theta_{\mathrm{S}} \approx 0.5\right)$. The desorption was carried out at $725 \mathrm{~K}$ (atoms and ions) and $880 \mathrm{~K}$ (atoms). Letters indicate the corresponding photographs in Fig. $4 \mathrm{e}$ and $\mathrm{f}$. 

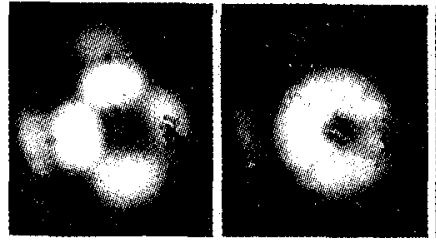

(a) $\mathrm{Ni}$

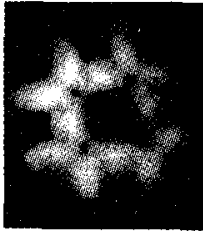

(d)

$$
\mathrm{S} / \mathrm{Ni}
$$

(b) $t=15 \mathrm{~s}$

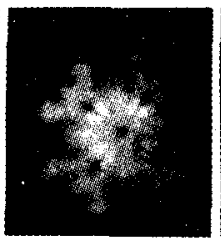

(e) $t=15 \mathrm{~s}$

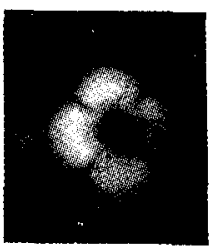

(c) $t=700 \mathrm{~s}$

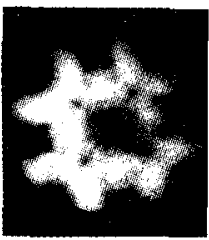

(f) $t=2000 s$

Fig. 4. Field emission patterns, characteristic of: (a) clean (001)-oriented nickel; (b) and (c) after desorption of potassium from clean nickel of (a) at $825 \mathrm{~K}$; (d) sulfur covered nickel $\left(\Theta_{\mathrm{S}} \approx 0.5\right)$; (e) and $(f)$ after desorption of potassium from sulfur covered nickel of (d) at $880 \mathrm{~K}$; $t$ represents the desorption time. The black spot on the right hand of each photograph is due to a fault in the phosphor screen and should be ignored.

The potassium desorption procedure was repeated for a higher sulfur coverage $\left(\Theta_{\mathrm{S}} \approx 1\right)$. In order to reach this coverage, the emitter was thermally cleaned at $1560 \mathrm{~K}$ for $10 \mathrm{~s}$ and then sulfur was deposited. The preannealing of the $\mathrm{Ni}(001)$ oriented emitter at this temperature led to a change in the orientation from the (001) to (111). Figure 5 shows an example of the $U$ versus $t$ curve for the total desorption from the $\mathrm{Ni}(111)$ emitter at $778 \mathrm{~K}$. Field emission pattern associated with the formation of the (111) oriented nickel emitter at $1560 \mathrm{~K}$ and some stages of the potassium desorption from the sulfur precovered $\mathrm{Ni}(111)$ emitter $\left(\Theta_{\mathrm{S}} \approx 1\right)$ are shown in Fig. 6a-f.

Arrhenius plots for the atomic and total desorption of potassium from the clean and the sulfur precovered Ni emitter are shown in Fig. 7. The calculated TD energies for atom and total desorption from clean $\mathrm{Ni}$ emitter are $E_{\mathrm{Ni}}^{\mathrm{a}}=3.8 \mathrm{eV}$ [(a) plot] and $E_{\mathrm{Ni}}^{\mathrm{a}+\mathrm{i}}=2.5 \mathrm{eV}$ [(a') plot], respectively, but these for atom and total desorption from sulfur precovered $\mathrm{Ni}$ emitter $\left(\Theta_{\mathrm{S}} \approx 0.5\right)$ are $E_{\mathrm{S} / \mathrm{Ni}}^{\mathrm{a}}=3.0 \mathrm{eV}$ [(b) plot] and $E_{\mathrm{S} / \mathrm{Ni}}^{\mathrm{a}+\mathrm{i}}=2.9 \mathrm{eV}\left[\left(\mathrm{b}^{\prime}\right)\right.$ plot] respectively. Also, the value of $E_{\mathrm{S}^{*} / \mathrm{Ni}}^{\mathrm{a}}=$ $4.1 \mathrm{eV}$ was found for average sulfur coverage of $\Theta_{\mathrm{S}} \approx 1$ [( $\left.\mathbf{c}^{\prime}\right)$ plot in Fig. 4]. Energies $E$ and average work function $\Phi$ [calculated from the relation $\Phi=$ $\Phi_{\text {clean }}\left(U / U_{\text {clean }}\right)^{2 / 3}$ ] are gathered in Table.

According to the model of Gurney [5] interaction of alkali-metal atoms with the metallic substrate was described on the basis of electron charge transfer from the adatoms to the substrate. In consequence, the alkali-metal atoms are positively charged, which leads to the negative charge density in the substrate. This effect strongly depends on the substrate work function, ionization potential of the alkali atom and the coverage [6]. In contrast to this picture a different model was 


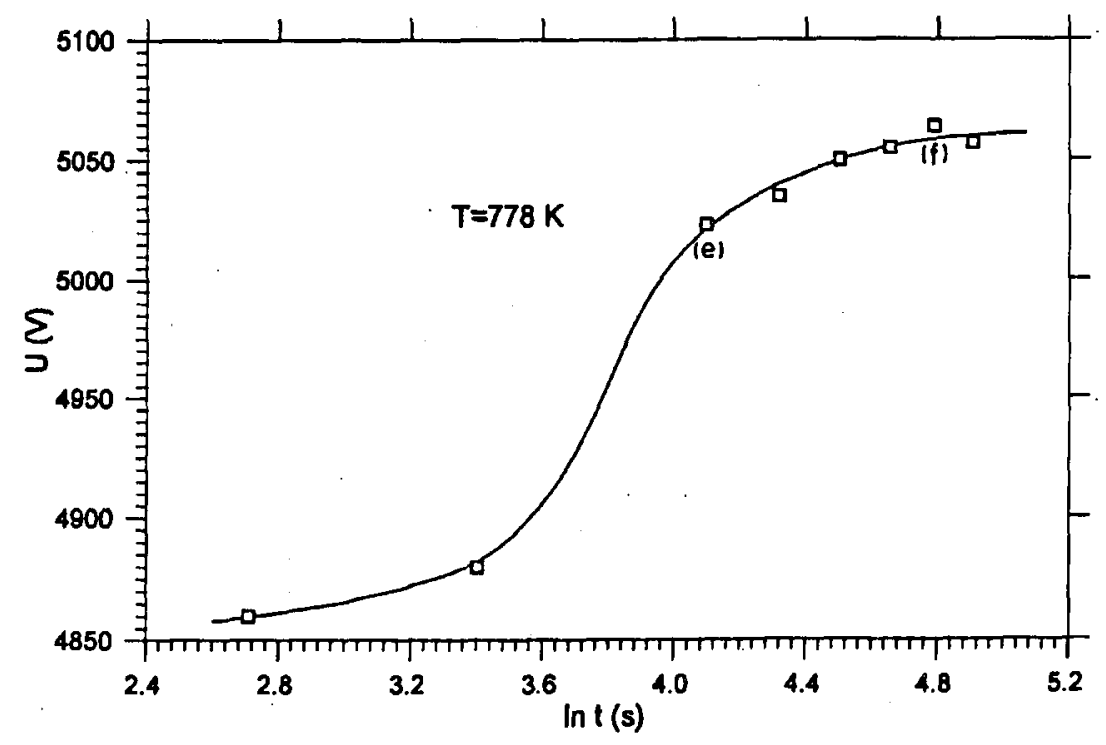

Fig. 5. Voltage $U$ required to maintain a constant emission current as a function of the desorption of atoms and ions from sulfur covered nickel $\left(\Theta_{S} \approx 1\right)$ at $778 \mathrm{~K}$. Letters indicate the corresponding photographs in Fig. $6 \mathrm{e}$ and $\mathrm{f}$.

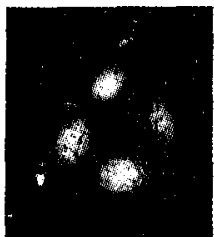

(a) $\mathrm{Ni}$

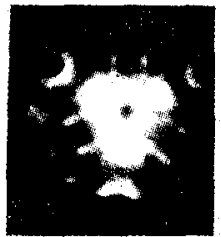

(d) $t=0$

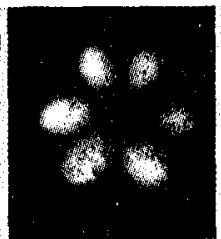

(b) $\mathrm{Ni}$

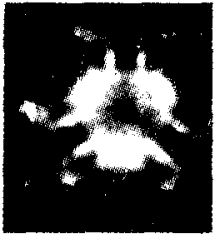

(e) $t=60 s$

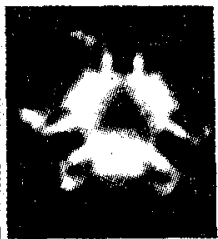

(c) $\mathrm{S} / \mathrm{Ni}$

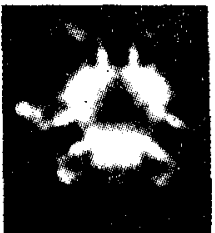

(f) $t=120 \mathrm{~s}$

Fig. 6. Field emission patterns, characteristic of: (a) the (001)-oriented nickel, showing the (111) twin boundary in the upper left-hand corner after heating of the sulfur covered nickel of Fig. 4d at $1560 \mathrm{~K}$; (b) clean (111)-oriented nickel, which was obtained after successive heating of the specimen of Fig. 6 a at $1560 \mathrm{~K}$; (c) sulfur covered nickel $\left(\Theta_{\mathrm{S}} \approx 1\right)$ of (b); (d) after equilibration of one potassium dose $\left(\Theta_{\mathrm{K}} \approx 0.02\right)$ on the surface of (c); (e) and (f) after potassium desorption from sulfur covered nickel of (d) at $778 \mathrm{~K}$; $t$ represents the desorption time. The small black spots (cf. patterns (a) and (b)) are due to damage of the phosphor screen and should be ignored. 


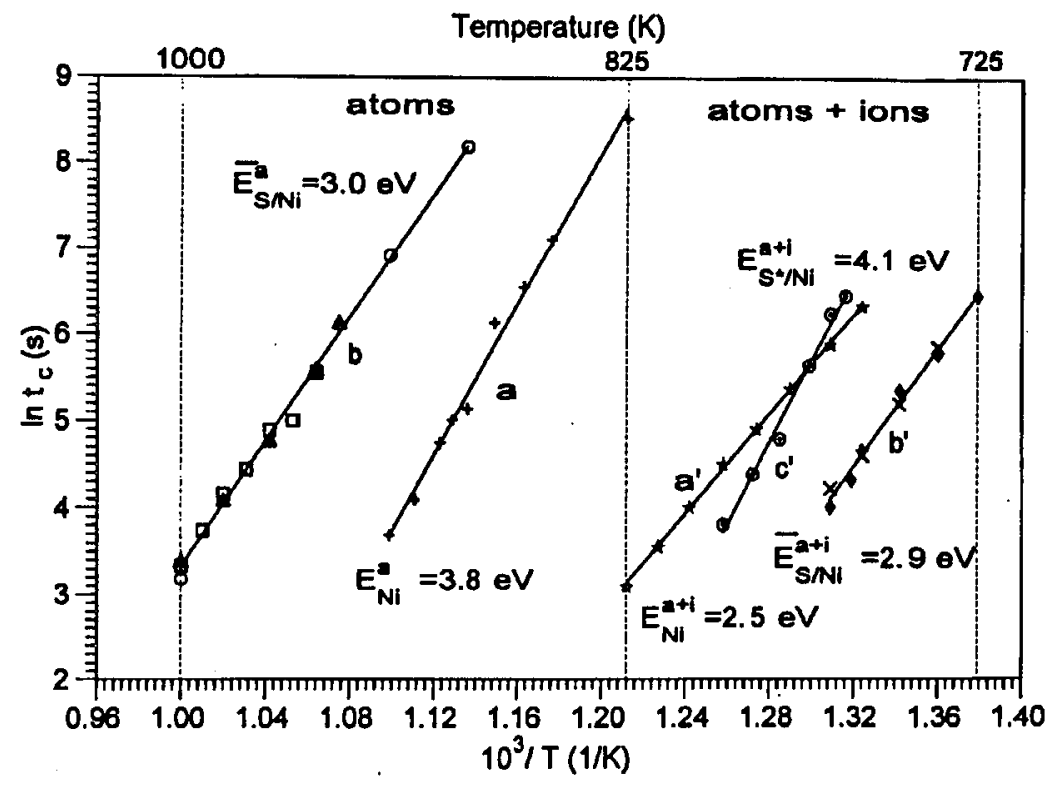

Fig. 7. Arrhenius plots for the process of desorption of potassium from clean nickel and from the sulfur covered nickel. Dashed line indicates two temperature regimes for the neutral and total desorption. Points marked by various symbols of the $b$ and $b^{\prime}$ plots represent separate experimental runs.

proposed by Ishida and Terakura $[7,8]$. According to their statement even at low coverage there is practically no charge transfer from the adsorbate to the substrate. Some experimental results $[9,10]$ seem to support the latter proposal. However, according to Scheffler and coworkers [11-13] there is no need to dismiss the idea of charge transfer and electronegativities contained in the model of Gurney and the idea is still most useful in order to describe isolated adsorbates on metals.

It should be noted that in the present experiments the activation energies for TD can correspond to average heat of adsorption within low-coverage range of potassium. The adsorption of potassium is not activated and it represents a spectrum of adsorption sites of different binding energy on a polycrystalline surface of an emitter. This problem was discussed in details by Schmidt and Gomer for the thermal desorption of $\mathrm{K}$ from $\mathrm{W}$ field emitter [14]. The desorption proceeded at constant temperature. Although the activation energy for desorption of $\mathrm{K}^{+}$cannot be determined in this experiment, the activation energy for the total desorption (neutrals and ions) $E^{\mathrm{a}+\mathrm{i}}$ reflects the desorption energy for potassium ions $E^{\mathrm{i}}$. For the above reasons only some qualitative discussion in terms of Gurney's model is carried on.

\section{1. $K / N i$}

Table shows that for the clean nickel $E_{\mathrm{Ni}}^{\mathrm{a}}>E_{\mathrm{Ni}}^{\mathrm{a}}$. . Such relation is in good agreement with results for the $\mathrm{K} / \mathrm{W}$ system [14] and confirms the fact that the 
TABLE

Activation energy for thermal desorption of potassium from clean and sulfur covered surfaces of nickel, $E$, and the average work function $\Phi$. Potassium coverage $\Theta_{\mathrm{K}} \approx 0.2$.

\begin{tabular}{c|c|c|c}
\hline \hline $\begin{array}{c}\text { Average sulfur } \\
\text { coverage }\end{array}$ & $\begin{array}{c}\text { Average work } \\
\text { function } \\
\Theta_{\mathrm{S}}\end{array}$ & \multicolumn{2}{|c}{ Activation energy } \\
\cline { 3 - 4 } & $\Phi[\mathrm{eV}]$ & $\begin{array}{c}\text { atoms } \\
E^{\mathrm{a}}[\mathrm{eV}]\end{array}$ & $\begin{array}{c}\text { atoms }+ \text { ions } \\
E^{\mathrm{a}+\mathrm{i}}[\mathrm{eV}]\end{array}$ \\
\hline 0 & 4.5 & $3.8 \pm 0.2$ & $2.5 \pm 0.1$ \\
0.5 & 4.8 & $3.0 \pm 0.1$ & $2.9 \pm 0.2$ \\
1 & 5.1 & - & $4.1 \pm 0.3$
\end{tabular}

alkali adsorbates can be adsorbed on metals as ions (cations). This effect generally is the result of the relatively high work function $\phi$ of some single planes of nickel, particularly $\{111\}$ and $\{100\}$ (from 5.2 to $5.56 \mathrm{eV}$ and 5.1 to $5.22 \mathrm{eV}$, respectively [15]) with respect to the ionization potential of potassium $I=4.34 \mathrm{eV}$. At the beginning of the adsorption the adsorbate could be accumulatcd on these planes under the diffusion equilibrium conditions $[2,16]$. In the rough approximation the results are in agreement with the relation

$$
E^{\mathrm{i}}=E^{\mathrm{a}}+I-\phi .
$$

The obtained value of $E_{\mathrm{Ni}}^{\mathrm{a}+\mathrm{i}}=2.5 \mathrm{eV}$ is close to other results concerning the activation energy for desorption of potassium, e.g. from tungsten emitter $(2.2 \mathrm{eV})$ [5], from polycrystalline iron (2.6 eV) [17], from (100) plane of $\mathrm{Pd}(2.49 \mathrm{eV})$ [18] and also from the (110) plane of $\mathrm{Ni}(2.56 \mathrm{eV})[19]$.

\section{2. $K-S / N i$}

The changes of the desorption parameters listed in Table, occur as the result of the changes in chemical properties of the substrate and the sulfur-affected distribution of the surface density of potassium. As it is shown in Table the sulfur deposition causes an increase in the average work function. Although the distribution of sulfur density on the nickel tip in the low coverage range under thermal equilibrium conditions is not known it follows from our previous observation that sulfur at the first stage occupies the high-index faces of $\mathrm{Ni}$ crystal [20]. This is in qualitative agreement with the field emission pattern: for a sulfur coverage of $\Theta_{\mathrm{S}}=0.5$ (Fig. 4d) the effect of sulfur adsorption consists in the darkening of vicinity of the (100) region and, consequently, the increase in the work function of this region is possible. The work function increase in this region can cause the increase in the ionization degree of potassium adatoms adsorbed on the sulfur precovered region. The situation is illustrated by field emission patterns in Fig. 4e and 4f. Visible changes occur on the (100) region with vicinal high-index planes.

This explanation is in accordance with the obtained activation energy for ionic value and atomic desorption at coverage $\Theta_{\mathrm{S}}=0.5$. Namely, for $\Theta_{\mathrm{S}}=0.5$ the ionic desorption from the clean, high work function planes of nickel (e.g. (100)) should be expected to be less probable on the basis of the relation (2). Indeed, this 
relation would give only $2.12 \mathrm{eV}$ for $E_{\mathrm{S} / \mathrm{Ni}}^{\mathrm{i}}=E_{\mathrm{S} / \mathrm{Ni}}^{\mathrm{a}}+I-\Phi$ (if $\Phi$ is assumed to be equal to $5.22 \mathrm{eV}$ ), which is clearly less than the obtained value $E_{\mathrm{S} / \mathrm{Ni}}^{\mathrm{a}+\mathrm{i}}=2.9 \mathrm{eV}$ (see Table). If the calculated value $E_{\mathrm{S} / \mathrm{N}}^{\mathrm{i}}=2.12 \mathrm{eV}$ is valid and the measured $E_{\mathrm{S} / \mathrm{Ni}}^{\mathrm{a}+\mathrm{i}}=2.9 \mathrm{eV}$ is correct, a spectrum of the desorbed $\mathrm{K}$-species would contain a considerable amount of atoms. This result would not be in agreement with the mechanism postulated [6]. On the other hand, for the high-index planes (where the work function increases with sulfur coverage) relation (2) can be more correct e.g. for $\Phi=4.8 \mathrm{eV}$ relation (2) gives $E_{\mathrm{S} / \mathrm{Ni}}^{\mathrm{i}}=2.54 \mathrm{eV}$ and this can suggest a higher ionic contribution to the $E_{\mathrm{S} / \mathrm{Ni}}^{\mathrm{a}}=2.9 \mathrm{eV}$ (Table).

The measurement for $\Theta_{\mathrm{S}} \approx 1$ provides still a higher value of $E_{\mathrm{S} / \mathrm{Ni}}^{\mathrm{a}}$. Unfortunately, the measurement for $E^{\text {a }}$ was not successful. In this case relation (2) gives $E_{\mathrm{S} / \mathrm{Ni}}^{\mathrm{a}}=4.82 \mathrm{eV}$.

Summarizing, our experimental data indicate that the presence of sulfur on the nickel tip surface causes the redistribution of potassium on the surface. It is also seen from Table that the thermal stability of potassium layers increases with sulfur coverage of the nickel tip.

\section{Acknowledgment}

The help of Dr. S. Surma in the preparation of the manuscript is gratefully acknowledged.

This work was supported by the University of Wrocław, project No. $2016 /$ W/IFD $/ 94$.

\section{References}

[1] M. Błaszczyszyn, Surf. Sci. 136, 103 (1984).

[2] M. Błaszczyszyn, Surf. Sci. 151, 351 (1985).

[3] M. Błaszczyszyn, R. Błaszczyszyn, R. Męclewski, A.J. Melmed, T.E. Madey, Surf. Sci. 131, 103 (1983).

[4] R. Błaszczyszyn, M. Błaszczyszyn, R. Męclewski, Surf. Sci. 51, 396 (1975).

[5] R.W. Gurney, Phys. Rev. 47, 479 (1935).

[6] T. Aruga, Y. Murata, Prog. Surf. 31, 61 (1989).

[7] H. Ishida, K. Terakura, Phys. Rev. B 38, 5752 (1988).

[8] H. Ishida, Phys. Rev. B 42, 10899 (1990).

[9] D.M. Riffe, G.K. Werheim, P.H. Citrin, Phys. Rev. Lett. 64, 571 (1990).

[10] M.-L. Shek, J. Hrbek, T.K. Sham, G.-Q. Xu, Phys. Rev. B 41, 3447 (1990).

[11] M. Scheffler, Ch. Droste, A. Fleszer, F. Maca, G. Wachulka, G. Barzel, Physica B 172, 143 (1991).

[12] C. Stampfl, J. Neugebauer, M. Schefller, Surf. Sci. 307-309, 8 (1994).

[13] J. Bormet, J. Neugebauer, M. Scheffler, Phys. Rev. B 49, 17242 (1994).

[14] L.D. Schmidt, R. Gomer, J. Chem. Phys. 42, 3573 (1965). 
[15] V.G. Fomienko, I.A. Podchernaeva, in: Emission Properties of Substances and Materials, Ed. G.W. Samsonov, Atomizdat, Moscow 1975, p. 125 (in Russian).

[16] M. Błaszczyszynowa, R. Błaszczyszyn, Acta Phys. Pol. A 81, 285 (1992).

[17] R.V. Hill, E.K. Stefanakos, R.F. Tinder, J. Appl. Phys. 43, 1976 (1972).

[18] A. Berko, F. Solymosi, Surf. Sci. 187, 359 (1987).

[19] R.L. Gerlach, T.N. Rhodin, Surf. Sci. 19, 403 (1970).

[20] M. Błaszczyszynowa, R. Błaszczyszyn, Vacuum 45, 229 (1994). 